\title{
A thermosensitive mutation alters the effects of lacosamide on slow inactivation in neuronal voltage-gated sodium channels, Nav1.2
}

\author{
Mena Abdelsayed ${ }^{\dagger}$, Stanislav Sokolov ${ }^{\dagger}$ and Peter C. Ruben * \\ Department of Biomedical Physiology and Kinesiology, Simon Fraser University, Burnaby, BC, Canada
}

\section{Edited by:}

Mohamed Chahine, Laval University,

Canada

Reviewed by:

Chris Ahern, University of British

Columbia, Canada

Alexandra Koschak, University

Innsbruck, Austria

*Correspondence:

Peter C. Ruben, Department of Biomedical Physiology and

Kinesiology, Simon Fraser

University, 8888 University Drive,

Burnaby, BC V5A 1S6, Canada

e-mail: pruben@sfu.ca

t These authors have contributed equally to this work.
Epilepsy is a disorder characterized by seizures and convulsions. The basis of epilepsy is an increase in neuronal excitability that, in some cases, may be caused by functional defects in neuronal voltage gated sodium channels $\left(\mathrm{Navs}_{\mathrm{v}}\right)$. The $\mathrm{C} 121 \mathrm{~W}$ mutation of the $\beta 1$ subunit, in particular, gives rise to the thermosensitive generalized epilepsy with febrile seizures plus (GEFS+) phenotype. Lacosamide is used to treat epileptic seizures and is distinct from other anti-seizure drugs by targeting Nav slow-inactivation. We studied the effects of a physiologically relevant concentration of lacosamide on the biophysical properties of Nav1.2 channels associated with either WT- $\beta 1$ or the mutant C121W- $\beta 1$ subunit. Biophysical parameters were measured at both normal $\left(22^{\circ} \mathrm{C}\right)$ and elevated $\left(34^{\circ} \mathrm{C}\right)$ temperatures to elicit the differential temperature-sensitivity of $\mathrm{C} 121 \mathrm{~W}$. Lacosamide was more effective in Nav1.2 associated with the WT- $\beta 1$ than with C121W- $\beta 1$ at either temperature. There is also a more potent effect by lacosamide on slow inactivation at elevated temperatures. Our data suggest a modulatory role is imparted by the $\beta 1$ subunit in the interaction between the drug and the channel.

Keywords: voltage-gated sodium channels, slow inactivation, lacosamide, GEFS + , thermosensitive, WT- $\beta 1$ (wild-type), C121W- $\beta 1$

\section{INTRODUCTION}

Epilepsy is a neurological disorder in which neuronal hyperexcitability causes convulsions and seizures. This disorder may be elicited via different mechanisms, some of which have genetic origins. There are over 150 described epileptogenic mutations in the $\mathrm{Na}_{V} 1.1$ isoform of the voltage-gated sodium channel $\left(\mathrm{Na}_{\mathrm{V}}\right)$, which is expressed in the central nervous system (Clare et al., 2000; Meisler and Kearney, 2005; Mantegazza et al., 2010). Eight epileptogenic mutations are associated with Nav1.2 (Meisler and Kearney, 2005). Several mutations/deletions in the auxiliary $\beta 1$ subunit give rise to generalized epilepsy with febrile seizures plus (GEFS+) (Wallace et al., 1998; Audenaert et al., 2003; Xu et al., 2007). The C121W- $\beta 1$ was the first of such mutations to be described (Wallace et al., 1998; Wimmer et al., 2010), and causes channel hyperexcitabilty at elevated temperatures. It was later demonstrated that the kinetics of recovery from the fast-inactivated state is enhanced at elevated temperatures $\left(34^{\circ} \mathrm{C}\right)$ when the $\mathrm{C} 121 \mathrm{~W}-\beta 1$ mutation is co-expressed with $\mathrm{Na}_{V} 1.2$ (Egri et al., 2012). The WT- $\beta 1$ subunit thus appears to have a thermoprotective function that is lost in C121W- $\beta 1$.

Two classes of anticonvulsants act on different time-scales of inactivation in neuronal $\mathrm{Na}_{V} s$. The classic anticonvulsants, including phenytoin, carbamazepine, and lamotrigine, stabilize the fast-inactivated state (Ragsdale et al., 1996; Ragsdale and Avoli, 1998; Lees and Shipton, 2009; Karoly et al., 2010). In fast inactivation, the IFMT motif in the cytoplasmic linker between domains III and IV occludes the pore of the channel in the millisecond time scale via thermodynamically favorable interactions with the inner vestibule of the channel (Ragsdale and Avoli, 1998; Clare et al., 2000; Denac et al., 2000; Yu et al., 2005; Catterall et al., 2012). Classic anticonvulsants bind within the inner vestibule of the channel forming interactions with the IFMT and fast-inactivation binding sites of the IFMT motif (Ragsdale and Avoli, 1998). A novel class of anticonvulsants, including lacosamide, act by a different mechanism to stabilize the slowinactivated state of $\mathrm{Na}_{V}$ s (Errington et al., 2008; Sheets et al., 2008; Lees and Shipton, 2009). Slow inactivation occurs over a hundred-milliseconds to seconds time scale through a combination of conformational rearrangements in the pore region and long distance interactions with other channel structures (O'reilly et al., 1999; Ong et al., 2000; McCollum et al., 2003; Zhang et al., 2003).

We tested the effects of lacosamide on $\mathrm{Na}_{\mathrm{V}} 1.2$ co-expressed with both WT- $\beta 1$ and $\mathrm{C} 121 \mathrm{~W}-\beta 1$ subunits, at normal $\left(22^{\circ} \mathrm{C}\right)$ and elevated temperatures $\left(34^{\circ} \mathrm{C}\right)$ to mimic the temperature sensitivity of GEFS+. We find the efficacy of lacosamide is lost with the C121W- $\beta 1$ mutation. This suggests the $\beta 1$ subunit modulates the interaction between lacosamide and the $\mathrm{Na}_{\mathrm{V}} 1.2 \alpha$-subunit.

\section{METHODS}

\section{CELL CULTURE}

Chinese hamster ovary $(\mathrm{CHO})$ cells stably expressing the rat $\mathrm{Na}_{V} 1.2$ channel (a gift from W.A. Catterall) were grown in filter sterilized DMEM/F12 (Invitrogen, Carlsbad, CA, USA) with glutamine, supplemented with $2 \mathrm{~g} / \mathrm{L} \mathrm{NaCHO} 3,100$ units/ml penicillin, $0.01 \mathrm{mg} / \mathrm{ml}$ streptomycin, $50 \mathrm{mg} / \mathrm{ml} \mathrm{G} 418$ at $\mathrm{pH} 7.4,5 \%$ FBS and maintained in a humidified environment at $37^{\circ} \mathrm{C}$ with 
$5 \% \mathrm{CO}_{2}$. Cells were plated on glass cover slips at a density conducive to single cell isolation.

\section{TRANSFECTION}

The stably expressing $\mathrm{Na}_{\mathrm{V}} 1.2$ cell line was transiently transfected with either WT- $\beta 1$ rat subunit ( $\mathrm{pBK} / \mathrm{CMV}$ vector) or the mutant rat ortholog of the $\mathrm{C} 121 \mathrm{~W}-\beta 1$ (pBK/CMV), and enhanced green fluorescent protein (eGFP) according to the PolyFect transfection protocol (Invitrogen).

\section{ELECTROPHYSIOLOGY}

Whole-cell recordings were performed in an extracellular solution containing (in $\mathrm{mM}$ ): $140 \mathrm{NaCl}, 4 \mathrm{KCl}, 2 \mathrm{CaCl}_{2}, 1 \mathrm{MgCl}_{2}, 10$ HEPES. Solutions were adjusted to $\mathrm{pH} 7.4$ with $\mathrm{CsOH}$. Patch pipettes were fabricated using a P-97 puller and borosilicate glass (Sutter Instruments, CA, USA) using a Model P-1000 Puller (Sutter Instruments), dipped in dental wax to reduce capacitance, and thermally polished to a resistance of 1.0-1.5 $\mathrm{M} \Omega$. Pipette (intracellular) solution was composed of the following (in $\mathrm{mM}$ ): $120 \mathrm{CsF}, 20 \mathrm{CsCl}, 10 \mathrm{NaCl}$, and $10 \mathrm{HEPES}$ adjusted to $\mathrm{pH} 7.4$ with $\mathrm{CsOH}$. Dimethyl sulfoxide (DMSO) was used as solvent for lacosamide and diluted in bath solution at $<$ 1:1000 (by volume) from stock to obtain a $100 \mu \mathrm{M}$ final drug concentration. Stock lacosamide solution was pre-aliquoted in extracellular solution. All recordings were made using an EPC-9 patch-clamp amplifier (HEKA Elektronik, Lambrecht, Germany) digitized at $200 \mathrm{kHz}$ via an ITC-16 interface (Instrutech, Great Neck, NY, USA). Voltage clamping and data acquisition were controlled using PatchMaster/FitMaster software (HEKA Elektronik, Lambrecht, Germany) running on an Apple iMac. Current was low-pass-filtered at $5 \mathrm{kHz}$. Leak subtraction was performed automatically by software using a $\mathrm{P} / 4$ procedure following the test pulse. Bath solution was maintained at $22^{\circ} \mathrm{C} \pm 0.2^{\circ} \mathrm{C}$ or $34^{\circ} \mathrm{C} \pm$ $0.2^{\circ} \mathrm{C}$ using a Peltier device controlled by an HCC-100A temperature controller (Dagan, Minneapolis, MN, USA). Experiments were not performed at higher temperatures because of inherent instability of the temperature controller and cell membranes beyond $34^{\circ} \mathrm{C}$.

Gigaohm seals were allowed to stabilize in the on-cell configuration for $1 \mathrm{~min}$ prior to establishing the whole-cell configuration. We ensured that cells used for recordings had $R$-series $<3.5 \mathrm{M} \Omega$ for recordings. Series resistance compensation up to $80 \%$ was used when necessary. All data were acquired $>5$ min after attaining the whole-cell configuration, and cells were allowed to incubate $5 \mathrm{~min}$ after drug application prior to data collection. Before each protocol, the membrane potential was hyperpolarized to $-110 \mathrm{mV}$ to insure complete removal of both fast-inactivation and slow-inactivation.

\section{ANALYSIS}

Analysis and graphing were done using FitMaster software (HEKA Elektronik, Lambrecht, Germany) and Igor Pro (Wavemetrics, Lake Oswego, OR, USA) with statistical information derived using InStat (Graphpad Software Inc., San Diego, CA, USA). All data acquisition and analysis programs were run on an Apple iMac (Apple Computer, Cupertino, CA). Exponential or Boltzmann fits were performed for individual data sets to obtain means for time constants, apparent valence $(\mathrm{z})$, and midpoints of voltage-dependence $\left(V_{1 / 2}\right)$. Statistical significance was accepted at $p<0.05$ using Student's unpaired " $t$ " tests with two-tailed $p$-values. All values reported are given as means \pm standard error of means.

\section{VOLTAGE PROTOCOLS Activation}

To determine the voltage dependence of activation, we measured the peak current amplitude at test pulse potentials ranging from $-80 \mathrm{mV}$ to $+60 \mathrm{mV}$ in increments of $+10 \mathrm{mV}$ for $20 \mathrm{~ms}$. Channel conductance $(\mathrm{G})$ was calculated from peak $I_{\mathrm{Na}}$.

$$
G_{\mathrm{Na}}=I_{\mathrm{Na}} / V-E_{\mathrm{Na}}
$$

where $G_{\mathrm{Na}}$ is conductance, $I_{\mathrm{Na}}$ is peak sodium current in response to the command potential $V$, and $E_{\mathrm{Na}}$ is the Nernst equilibrium potential. Calculated values for conductance were fit with the Boltzmann equation:

$$
G / G_{\max }=1 /\left(1+\exp \left[-z e_{0}\left[V_{m}-V_{1 / 2}\right] / k T\right]\right)
$$

where $G / G_{\max }$ is normalized conductance amplitude, $V_{m}$ is the command potential, $z$ is the apparent valence, $e_{0}$ is the elementary charge, $V_{1 / 2}$ is the midpoint voltage, $k$ is the Boltzmann constant, and $T$ is temperature in ${ }^{\circ} \mathrm{K}$.

\section{Steady-state fast inactivation}

The voltage-dependence of fast inactivation was measured by preconditioning the channels to a hyperpolarizing potential of $-130 \mathrm{mV}$ and then eliciting prepulse potentials that ranged from -130 to $+10 \mathrm{mV}$ in increments of $10 \mathrm{mV}$ for either $20 \mathrm{~ms}$ or $500 \mathrm{~ms}$, followed by a $10 \mathrm{~ms}$ test pulse during which the voltage was stepped to $0 \mathrm{mV}$. Normalized current amplitude as a function of voltage was fit using the Boltzmann equation:

$$
I / I_{\max }=1 /\left(1+\exp \left(-z e_{0}\left(V_{M}-V_{1 / 2}\right) / k T\right)\right.
$$

where $I_{\max }$ is the maximum test pulse current amplitude.

\section{Open-state fast inactivation}

Time constants for open state fast-inactivation were derived by fitting a single exponential function to the decay of current from the peak to the end of the depolarizing stimulus.

\section{Recovery from fast inactivation}

Channels were fast-inactivated during a $20 \mathrm{~ms}$ or $500 \mathrm{~ms}$ depolarizing step to $0 \mathrm{mV}$, and recovery was measured during a $19 \mathrm{~ms}$ test pulse to $0 \mathrm{mV}$ following a $-110 \mathrm{mV}$ recovery pulse for durations between 0 and $1.024 \mathrm{~s}$. Time constants of fast inactivation recovery showed two components and were fit using a double exponential equation:

$$
I=I_{\mathrm{ss}}+\alpha_{1} \exp \left(-t / \tau_{1}\right)+\alpha_{2} \exp \left(-t / \tau_{2}\right)
$$

where I is current amplitude, $I_{\mathrm{ss}}$ is the plateau amplitude, $\alpha_{1}$ and $\alpha_{2}$ are the amplitudes at time 0 for time constants $\tau_{1}$ and $\tau_{2}$, and $t$ is time. 


\section{Steady-state slow inactivation}

The voltage-dependence of slow inactivation was measured by preconditioning the cells $-130 \mathrm{mV}$ for $30 \mathrm{~s}$. We then delivered prepulse potentials from $-130 \mathrm{mV}$ to $+10 \mathrm{mV}$, alternating with every sweep, in increments of $20 \mathrm{mV}$. After the prepulse, a $100 \mathrm{~ms}$ pulse at $-130 \mathrm{mV}$ was applied to recover channels from fast inactivation prior to a $20 \mathrm{~ms}$ test pulse at $0 \mathrm{mV}$. Peak current amplitude during the test pulse was normalized to that measured following the most negative prepulse, and plotted as a function of prepulse potential. Steady-state slow inactivation curves were fit with the following modified Boltzmann equation that takes into account changes in the steady-state probability of slow inactivation:

$$
I / I_{\max }=\left(I_{1}-I_{2}\right) /\left(1+\exp \left(-z e_{0}\left(V_{\mathrm{m}}-V_{1 / 2}\right) / k T\right)+I_{2}\right.
$$

where $I / I_{\max }$ is the maximum probability, $I_{1}$ and $I_{2}$ are maximum and minimum values in the fit, respectively, $\mathrm{z}$ is apparent valence, $e_{0}$ is the elementary charge, $V_{\mathrm{m}}$ is the prepulse potential, $V_{1 / 2}$ is the midpoint voltage of the steady-state slow inactivation curve, $k$ is the Boltzmann constant, and $T$ is the absolute temperature.

\section{Onset of slow inactivation}

A $5 \mathrm{~ms}$ test pulse to $0 \mathrm{mV}$ measured the rate of slow-inactivation onset following a two-pulse protocol consisting of 0-64 s durations at the conditioning voltage $(0 \mathrm{mV})$ and a $100 \mathrm{~ms}$ or $2 \mathrm{~s}$ hyperpolarizing pulse to $-110 \mathrm{mV}$ ("recovery pulse"). Time constants of slow-inactivation onset as a function of time were fit using a double exponential equation.

\section{Recovery from slow inactivation}

Slow inactivation was induced with either a $500 \mathrm{~ms}$ or $8 \mathrm{~s}$ depolarizing pulse to $0 \mathrm{mV}$, after which the membrane was hyperpolarized to $-110 \mathrm{mV}$ for durations of $0.02-60 \mathrm{~s}$ and peak current was tested with a $5 \mathrm{~ms}$ pulse to $0 \mathrm{mV}$. Time constants of slow inactivation recovery, plotted as a function of time, were fit with a double exponential equation.

\section{RESULTS}

\section{ACTIVATION}

Lacosamide $(100 \mu \mathrm{M})$ caused no significant effect on the voltage dependence of activation. There were no significant shifts in the midpoint $\left(V_{1 / 2}\right)$ or apparent valence $(z)$ at either elevated or normal temperatures in the WT- $\beta 1$ and the $C 121 \mathrm{~W}-\beta 1$ subunits (Table 1). Current traces from the four experimental conditions are shown in Figure 1.

\section{FAST INACTIVATION}

Lacosamide did not cause significant shifts in the kinetics of open state fast inactivation parameters in $\mathrm{Na}_{\mathrm{V}} 1.2$ co-expressed with either WT- $\beta 1$ or C121W- $\beta 1$ (Table 2 ). We examined steady-state fast inactivation with both $20 \mathrm{~ms}$ and $500 \mathrm{~ms}$ prepulse duration. There were no statistically significant shifts in the midpoint or apparent valence between control and $100 \mu \mathrm{M}$ lacosamide for

Table 1 | Activation parameters.

\begin{tabular}{|c|c|c|c|}
\hline & $V_{1 / 2}(\mathrm{mV})$ & $z$ (slope) & $n$ \\
\hline \multicolumn{4}{|l|}{$22^{\circ} \mathrm{C}$} \\
\hline WT- $\beta 1$ Control & $-19.4 \pm 0.7$ & $4.1 \pm 0.2$ & 12 \\
\hline WT- $\beta 1$ Drug & $-19.2 \pm 2.0$ & $3.7 \pm 0.2$ & 6 \\
\hline C121W- $\beta 1$ Control & $-16.0 \pm 1.0$ & $3.3 \pm 0.1$ & 10 \\
\hline C121W- $\beta 1$ Drug & $-16.8 \pm 1.2$ & $3.5 \pm 0.4$ & 6 \\
\hline \multicolumn{4}{|l|}{$34^{\circ} \mathrm{C}$} \\
\hline WT- $\beta 1$ Control & $-19.7 \pm 0.4$ & $6.1 \pm 0.2$ & 17 \\
\hline WT- $\beta 1$ Drug & $-21.1 \pm 0.5$ & $6.6 \pm 0.3$ & 11 \\
\hline C121W- $\beta 1$ Control & $-18.8 \pm 0.3$ & $7.1 \pm 0.2$ & 19 \\
\hline C121W- $\beta 1$ Drug & $-21.5 \pm 0.6$ & $6.3 \pm 0.4$ & 9 \\
\hline
\end{tabular}
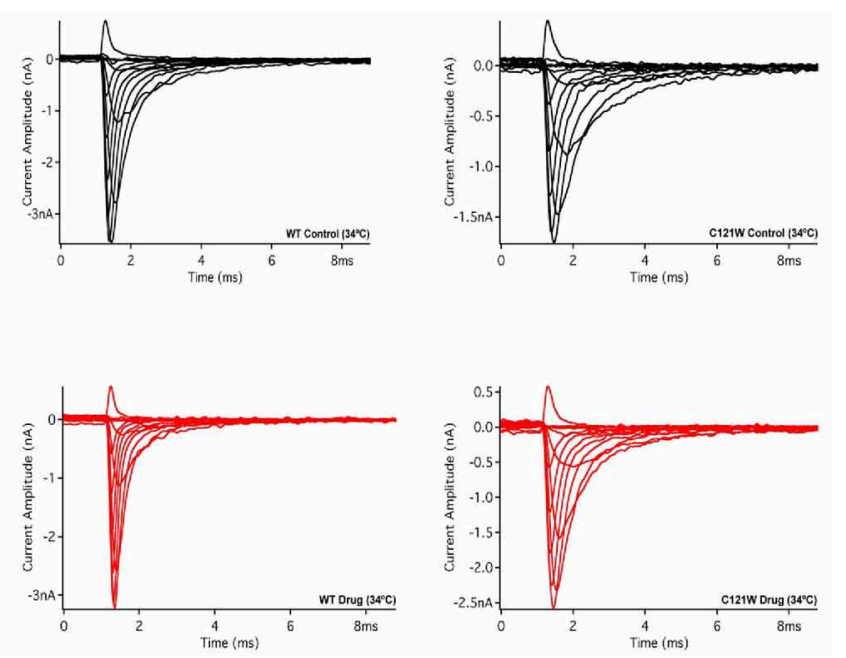
0 6 1 (1) 9
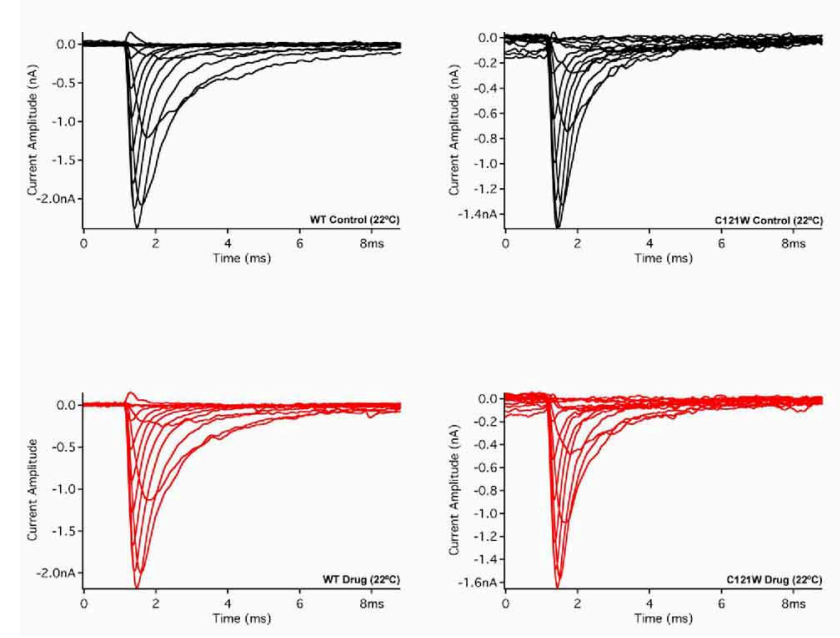

FIGURE 1 | Macroscopic currents. Current amplitude plotted verses time duration (ms). These traces were elicited by a set of alternating test pulses that range from $-80 \mathrm{mV}$ to $+60 \mathrm{mV}$ in increments of $+10 \mathrm{mV}$. 
Table 2 | Open-state fast inactivation.

\begin{tabular}{|c|c|c|c|c|c|c|}
\hline & $\tau-20 \mathrm{mV}(\mathrm{ms})$ & $\tau-10 \mathrm{mV}(\mathrm{ms})$ & $\tau 0 \mathrm{mV}(\mathrm{ms})$ & $\tau 10 \mathrm{mV}(\mathrm{ms})$ & $\tau 20 \mathrm{mV}(\mathrm{ms})$ & $n$ \\
\hline \multicolumn{7}{|l|}{$22^{\circ} \mathrm{C}$} \\
\hline WT- $\boldsymbol{\beta} 1$ Control & $1.29 \pm 0.11$ & $0.72 \pm 0.05$ & $0.51 \pm 0.04$ & $0.38 \pm 0.03$ & $0.34 \pm 0.02$ & 8 \\
\hline C121W- $\boldsymbol{\beta} 1$ Control & $1.03 \pm 0.13$ & $0.70 \pm 0.07$ & $0.52 \pm 0.04$ & $0.42 \pm 0.05$ & $0.39 \pm 0.03$ & 7 \\
\hline C121W-ק1 Drug & $1.09 \pm 0.10$ & $0.72 \pm 0.04$ & $0.54 \pm 0.03$ & $0.47 \pm 0.03$ & $0.39 \pm 0.02$ & 5 \\
\hline WT- $\beta 1$ Drug & $0.55 \pm 0.05$ & $0.37 \pm 0.02$ & $0.28 \pm 0.02$ & $0.23 \pm 0.02$ & $0.19 \pm 0.01$ & 11 \\
\hline C121W- $\boldsymbol{\beta} 1$ Control & $0.89 \pm 0.06$ & $0.57 \pm 0.04$ & $0.42 \pm 0.02$ & $0.34 \pm 0.02$ & $0.29 \pm 0.02$ & 18 \\
\hline C121W- $\boldsymbol{\beta} 1$ Drug & $0.89 \pm 0.06$ & $0.66 \pm 0.05$ & $0.51 \pm 0.04$ & $0.41 \pm 0.04$ & $0.35 \pm 0.03$ & 13 \\
\hline
\end{tabular}

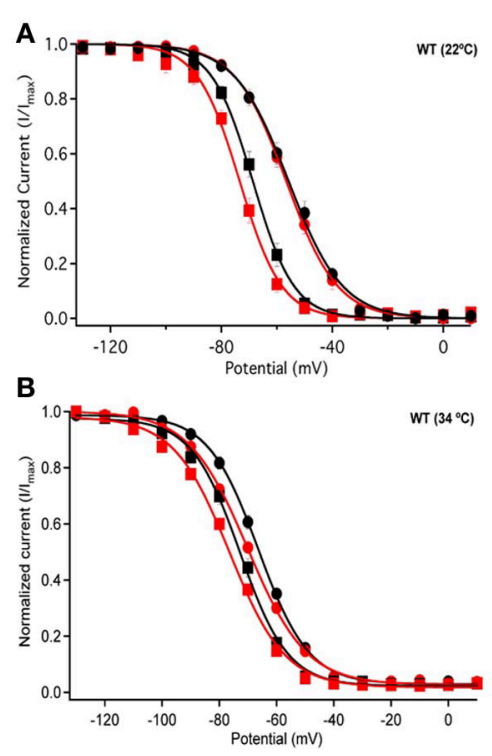

FIGURE 2 | Steady-state fast inactivation. Normalized current is plotted against a range of prepulse potentials $(\mathrm{mV})$. Steady-state fast inactivation was elicited by both $20 \mathrm{~ms}$ prepulse durations (filled circles) and $500 \mathrm{~ms}$ prepulse durations (filled squares). For both WT at $22^{\circ} \mathrm{C}$ and $34^{\circ} \mathrm{C}(\mathbf{A}, \mathbf{B})$

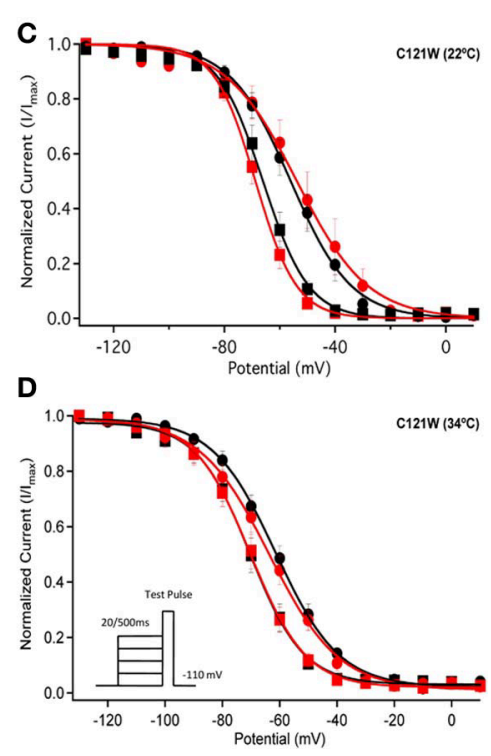

and $\mathrm{C} 121 \mathrm{~W}$ at $22^{\circ} \mathrm{C}$ and $34^{\circ} \mathrm{C}$ (C,D). The means of control (shown in black) were compared to $100 \mu \mathrm{M}$ Lacosamide (shown in red). In panel (D), an inset shows the pulse protocol used to measure steady-state fast inactivation.
WT- $\beta 1$ at $22^{\circ} \mathrm{C}$ with prepulse durations of $20 \mathrm{~ms}$ (Figure 2A, Table 3). At $34^{\circ} \mathrm{C}$ there was a significant shift in the midpoint value (Figure 2B, Table 3). However, there was no shift in the apparent valence with drug perfusion. Stabilization of steady-state fast inactivation was observed with $500 \mathrm{~ms}$ prepulse depolarizations. At both $22^{\circ} \mathrm{C}$ and $34^{\circ} \mathrm{C}$, there were significant hyperpolarizing shifts in the midpoint $\left(V_{1 / 2}\right)$ values with the WT- $\beta 1$ (Figures 2A,B, Table 3). There were no significant differences in the apparent valence when comparing temperature (Table 3).

In contrast, there were no significant shifts observed in the $V_{1 / 2}$ or apparent valence values of $\mathrm{C} 121 \mathrm{~W}-\beta 1$ with $100 \mu \mathrm{M}$ lacosamide using $20 \mathrm{~ms}$ or $500 \mathrm{~ms}$ prepulse durations at $22^{\circ} \mathrm{C}$ or $34^{\circ} \mathrm{C}$ (Figures 2C,D and Table 3).

We examined the recovery kinetics of fast inactivation with both $20 \mathrm{~ms}$ and $500 \mathrm{~ms}$ prepulse durations. Peak current amplitudes in the second depolarizing pulse of a double-pulse protocol, plotted as a function of interpulse duration, were fit with a double exponential function. We compared the fast $\left(\tau_{\mathrm{f}}\right)$ and slow $\left(\tau_{\mathrm{s}}\right)$ time constants and amplitudes, and the asymptote $\left(y_{0}\right)$ values. There were no significant shifts in the kinetics of fast inactivation recovery at $22^{\circ} \mathrm{C}$ and $34^{\circ} \mathrm{C}$ with $20 \mathrm{~ms}$ prepulse durations (Figure 3, Table 4). With $500 \mathrm{~ms}$ prepulses at $34^{\circ} \mathrm{C}$, there was a significant decrease in the amplitude of the fast recovery component with $100 \mu \mathrm{M}$ lacosamide and also a significant decrease in the plateau $y_{0}$ value (Table 4 ).

In contrast, we observed no statistically significant differences in any of the fast inactivation recovery kinetic parameter at either $22^{\circ} \mathrm{C}$ or $34^{\circ} \mathrm{C}$ in the $\mathrm{C} 121 \mathrm{~W}-\beta 1$ mutation (Figures 3C,D, Table 4) with both $20 \mathrm{~ms}$ and $500 \mathrm{~ms}$ prepulse durations.

\section{SLOW INACTIVATION}

We examined onset kinetics of slow inactivation with either $100 \mathrm{~ms}$ or $2 \mathrm{~s}$ recovery pulse following conditioning 
Table 3 | Steady-state fast inactivation parameters.

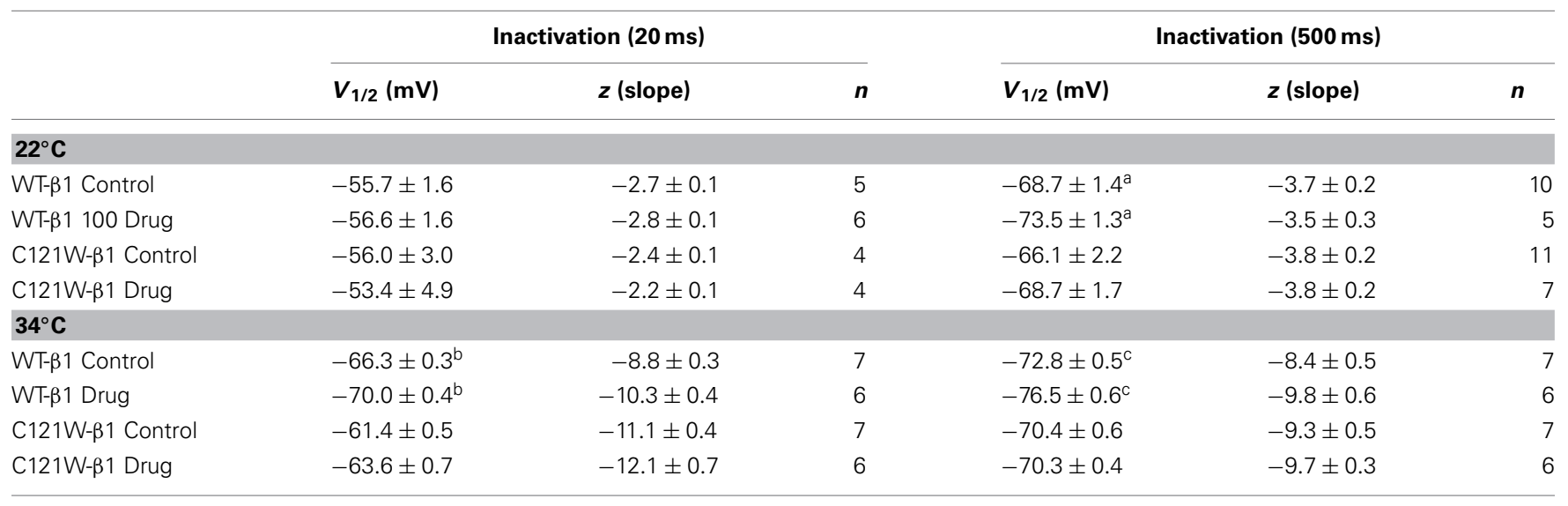

${ }^{a} P<0.05$ vs. WT- $\beta 1$ Control at $22^{\circ} \mathrm{C}$.

${ }^{b} P<0.01$ vs. WT- $\beta 1$ Control at $34^{\circ} \mathrm{C}$.

${ }^{c} P<0.05$ vs. WT $\beta 1$ Control at $34^{\circ} \mathrm{C}$.
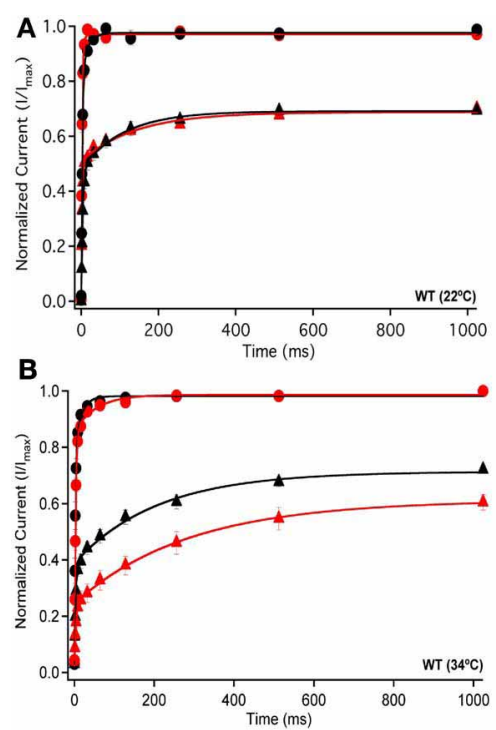

FIGURE 3 | Fast inactivation recovery. Normalized Current is plotted against a range of recovery durations (ms). Filled circles shows fast inactivation recovery elicited by $20 \mathrm{~ms}$ prepulse durations; whereas closed triangles represent prepulse durations of $500 \mathrm{~ms}$. For both $\mathrm{WT}$ at $22^{\circ} \mathrm{C}$ and

depolarizations of varying durations. At $22^{\circ} \mathrm{C}$ the changes induced by $100 \mu \mathrm{M}$ lacosamide were not statistically significant in either the C121W- $\beta$ 1or WT- $\beta 1$ co-expressed channels (Figures 4A,C, Table 5). Significant alterations of onset kinetics were observed at $34^{\circ} \mathrm{C}$ with the WT- $\beta 1$ subunit. With the $2 \mathrm{~s}$ recovery pulse we observed an increase in the amplitude of the fast onset component as well as a decrease in the plateau $y_{0}$ value (Figure 4B, Table 5). This trend was also observed for the $100 \mathrm{~ms}$ recovery pulse, but turned out to be not statistically significant. C121W- $\beta 1$ co-expressed channels demonstrated no significant changes in the onset kinetics with drug perfusion at $34^{\circ} \mathrm{C}$ with either recovery pulse duration (Figure 4D, Table 5).

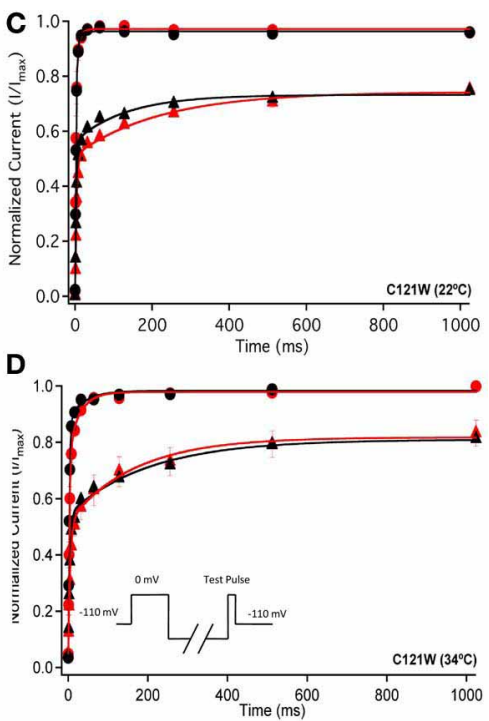

$34^{\circ} \mathrm{C}(\mathbf{A}, \mathbf{B})$ and $\mathrm{C} 121 \mathrm{~W}$ at $22^{\circ} \mathrm{C}$ and $34^{\circ} \mathrm{C}(\mathbf{C}, \mathbf{D})$. The means of control (shown in black) were compared to $100 \mu \mathrm{M}$ lacosamide (shown in red). Panel (D) shows an inset of the double pulse protocol measuring fast inactivation recovery.

We next examined the voltage-dependence of steady-state slow inactivation. We observed significant effects of lacosamide at elevated and normal temperatures in the presence of the WT$\beta 1$ subunit. At $22^{\circ} \mathrm{C}$ there was a $\sim 7 \mathrm{mV}$ hyperpolarizing shift in steady-state slow inactivation in $100 \mu \mathrm{M}$ lacosamide (Figure 5A, Table 6). This hyperpolarized shift was exacerbated at $34^{\circ} \mathrm{C}$ (Figure 5B, Table 6). The maximum probability of steady-state slow inactivation also increased significantly in the presence of the drug at $34^{\circ} \mathrm{C}$ (Table 6). C121W- $\beta 1$ co-expressed channels exhibited no significant shifts in the $V_{1 / 2}$, apparent valence, or the plateau values of steady-state slow inactivation at either $22^{\circ} \mathrm{C}$ or $34^{\circ} \mathrm{C}$ with the perfusion of $100 \mu \mathrm{M}$ lacosamide (Figures 5C,D, Table 6). 
Table 4 | Fast inactivation recovery.

\begin{tabular}{|c|c|c|c|c|c|c|c|c|c|c|c|c|}
\hline & \multicolumn{6}{|c|}{ Recovery (20 ms) } & \multicolumn{6}{|c|}{ Recovery $(500 \mathrm{~ms})$} \\
\hline \multicolumn{13}{|l|}{$22^{\circ} \mathrm{C}$} \\
\hline WT- $\beta 1$ Control & $2.7 \pm 0.3$ & $0.82 \pm 0.07$ & $17.3 \pm 9.5$ & $0.15 \pm 0.07$ & $0.98 \pm 0.01$ & 5 & $3.7 \pm 0.1^{a}$ & $0.48 \pm 0.01$ & $110.2 \pm 10.1$ & $0.21 \pm 0.01$ & $0.69 \pm 0.01$ & 5 \\
\hline WT- $\beta 1$ Drug & $1.6 \pm 0.7$ & $0.71 \pm 0.07$ & $3.6 \pm 4.0$ & $0.25 \pm 0.07$ & $0.97 \pm 0.01$ & 6 & $2.0 \pm 0.1^{a}$ & $0.51 \pm 0.02$ & $140.5 \pm 28.8$ & $0.18 \pm 0.01$ & $0.69 \pm 0.01$ & 5 \\
\hline C121W- $\beta 1$ Control & $2.4 \pm 0.4$ & $0.83 \pm 0.20$ & $7.4 \pm 7.9$ & $0.12 \pm 0.20$ & $0.96 \pm 0.01$ & 4 & $3.3 \pm 0.3$ & $0.56 \pm 0.02$ & $133.7 \pm 35.8$ & $0.17 \pm 0.02$ & $0.73 \pm 0.01$ & 6 \\
\hline WT- $\beta 1$ Control & $1.8 \pm 0.1$ & $0.75 \pm 0.04$ & $17.0 \pm 4.0$ & $0.20 \pm 0.04$ & $0.98 \pm 0.01$ & 6 & $3.3 \pm 0.3$ & $0.36 \pm 0.01^{b}$ & $207.0 \pm 24.0$ & $0.33 \pm 0.01$ & $0.71 \pm 0.01^{b}$ & 7 \\
\hline WT- $\beta 1$ Drug & $2.1 \pm 0.2$ & $0.82 \pm 0.03$ & $23.0 \pm 9.0$ & $0.13 \pm 0.03$ & $0.99 \pm 0.01$ & 8 & $3.7 \pm 0.3$ & $0.20 \pm 0.01^{b}$ & $285.0 \pm 15.0$ & $0.37 \pm 0.01$ & $0.61 \pm 0.01^{b}$ & 6 \\
\hline C121W- $\beta 1$ Control & $2.5 \pm 0.2$ & $0.85 \pm 0.03$ & $40.0 \pm 21.0$ & $0.11 \pm 0.03$ & $0.98 \pm 0.01$ & 7 & $3.9 \pm 0.4$ & $0.51 \pm 0.02$ & $200.0 \pm 44.0$ & $0.26 \pm 0.02$ & $0.81 \pm 0.02$ & 7 \\
\hline 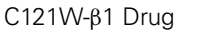 & $3.1 \pm 0.3$ & $0.73 \pm 0.05$ & $29.0 \pm 9.0$ & $0.21 \pm 0.05$ & $0.98 \pm 0.01$ & 8 & $4.2 \pm 0.6$ & $0.47 \pm 0.03$ & $184.0 \pm 32.0$ & $0.32 \pm 0.03$ & $0.82 \pm 0.01$ & 6 \\
\hline
\end{tabular}

a $P<0.001$ vs. WT- $\beta 1100 \mu \mathrm{M}$ Lacosamide at $22^{\circ} \mathrm{C}$.

${ }^{b} P<0.001$ vs. WT $\beta 1100 \mu \mathrm{M}$ Lacosamide at $34^{\circ} \mathrm{C}$.
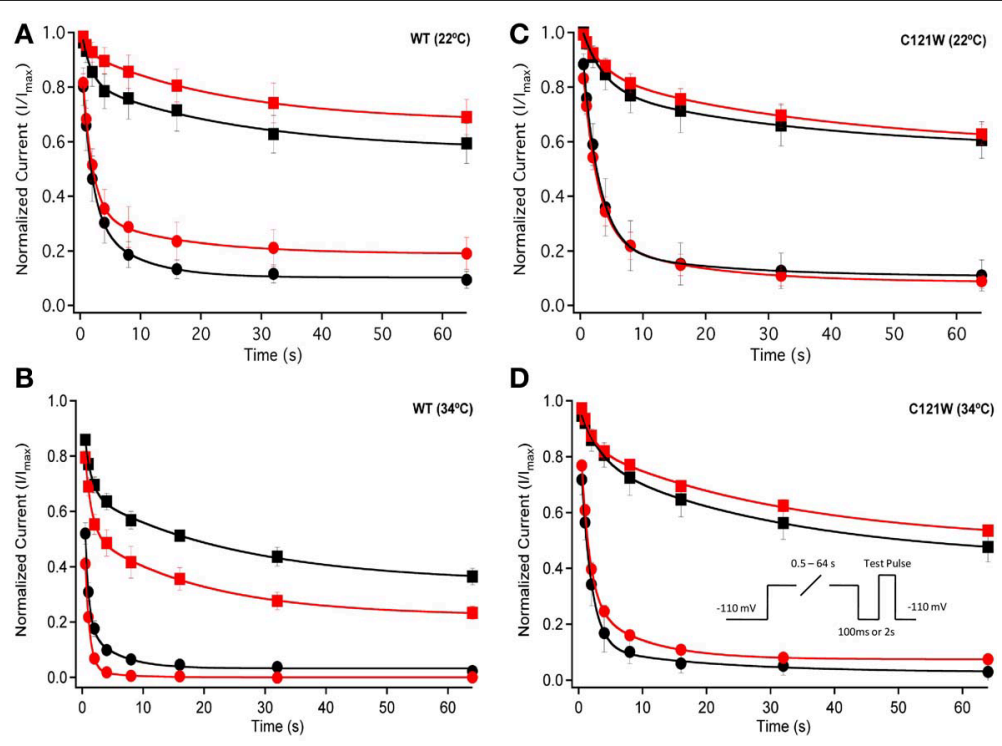

FIGURE 4 | Slow inactivation onset. Normalized Current is plotted against a range of onset durations (s). We show two different recovery pulse durations: $100 \mathrm{~ms}$ (filled squares) and $2 \mathrm{~s}$ (filled circles) in control

(black) and $100 \mu \mathrm{M}$ lacosamide (red). For both $\mathrm{WT}$ at $22^{\circ} \mathrm{C}$ and $34^{\circ} \mathrm{C}$ $(\mathbf{A}, \mathbf{B})$ and $\mathrm{C} 121 \mathrm{~W}$ at $22^{\circ} \mathrm{C}$ and $34^{\circ} \mathrm{C}(\mathbf{C}, \mathbf{D})$. Inset in (D) shows the pulse protocol.

We also measured recovery from slow inactivation and drug block using both $500 \mathrm{~ms}$ and $8 \mathrm{~s}$ conditioning depolarizing pulses. At $22^{\circ} \mathrm{C}$ we did not observe any significant differences in any of the kinetic parameters of recovery with either $500 \mathrm{~ms}$ or $8 \mathrm{~s}$ depolarization durations with WT- $\beta 1$ or $\mathrm{C} 121 \mathrm{~W}-\beta 1$ subunits with the addition $100 \mu \mathrm{M}$ lacosamide (Figures 6A,C, Table 7). WT- $\beta 1$ but not C121W- $\beta 1$ co-expressed channels demonstrated a significant deceleration of recovery with drug perfusion at $34^{\circ} \mathrm{C}$ (Figures 6B,D, Table 7).

\section{DISCUSSION}

In this study we established the role of sodium channel $\beta 1$ subunit in modulating the effects of a physiologically relevant concentration of lacosamide on the biophysical properties of the brain sodium channel, Nav1.2. We also tested the functional effects C121W, a mutation in the $\beta 1$ subunit which causes GEFS+ phenotype (Wallace et al., 1998), on the ability of lacosamide to inhibit sodium currents.

Similar to previous observations of Errington et al. (2008) and Sheets et al. (2008), we found that lacosamide caused no significant changes in the voltage dependence of $\mathrm{Na}_{V} 1.2$ activation or kinetics of fast inactivation with either the WT- $\beta 1$ or C121W- $\beta 1$ subunits. Also there were no measurable differences in activation between the WT and the mutant C121W- $\beta 1$ subunits. This result is consistent with findings of Qin et al. (2003) and Egri et al. (2012), who reported no effect on activation upon co-expression of the $\beta 1$ subunit.

Lacosamide is postulated to be a slow inactivation-selective drug (Errington et al., 2008; Sheets et al., 2008) that does not affect fast inactivation mechanism but exerts its inhibitory effects on the time scale of seconds, far slower than that for many other "classic" anticonvulsants such as phenytoin, carbamazepine, and 
Table 5 | Slow inactivation onset.

\begin{tabular}{|c|c|c|c|c|c|c|c|c|c|c|c|}
\hline & \multicolumn{5}{|c|}{ Onset (100 ms) } & \multicolumn{6}{|c|}{ Onset (2s) } \\
\hline \multicolumn{12}{|l|}{$22^{\circ} \mathrm{C}$} \\
\hline WT- $\beta 1$ Control & $1.5 \pm 0.3$ & $0.47 \pm 0.08$ & $7.6 \pm 2.3$ & $0.23 \pm 0.08$ & $0.10 \pm 0.01$ & $1.48 \pm 0.62$ & $0.16 \pm 0.03$ & $25.8 \pm 11.7$ & $0.25 \pm 0.03$ & $0.57 \pm 0.04$ & 5 \\
\hline WT- $\beta 1$ Drug & $1.6 \pm 0.1$ & $0.48 \pm 0.02$ & $15.1 \pm 4.2$ & $0.14 \pm 0.02$ & $0.19 \pm 0.07$ & $1.03 \pm 0.21$ & $0.10 \pm 0.01$ & $23.9 \pm 1.6$ & $0.26 \pm 0.01$ & $0.67 \pm 0.01$ & 5 \\
\hline C121W- $\beta 1$ Control & $2.6 \pm 0.2$ & $0.68 \pm 0.04$ & $19.4 \pm 13.7$ & $0.10 \pm 0.04$ & $0.11 \pm 0.01$ & $3.35 \pm 0.46$ & $0.20 \pm 0.02$ & $33.7 \pm 10.0$ & $0.22 \pm 0.01$ & $0.57 \pm 0.02$ & 5 \\
\hline WT- $\beta 1$ Control & $0.59 \pm 0.10$ & $0.34 \pm 0.04$ & $4.2 \pm 1.5$ & $0.15 \pm 0.04$ & $0.03 \pm 0.01$ & $1.10 \pm 0.20$ & $0.19 \pm 0.02^{\mathrm{a}}$ & $25.0 \pm 5.0$ & $0.32 \pm 0.02$ & $0.34 \pm 0.02^{b}$ & 8 \\
\hline WT- $\beta 1$ Drug & $0.73 \pm 0.10$ & $0.38 \pm 0.01$ & $5.4 \pm 1.9$ & $0.03 \pm 0.01$ & $0.00 \pm 0.01$ & $1.00 \pm 0.20$ & $0.28 \pm 0.02^{\mathrm{a}}$ & $19.0 \pm 3.0$ & $0.30 \pm 0.02$ & $0.22 \pm 0.01^{b}$ & 6 \\
\hline C121W- $\beta 1$ Control & $1.60 \pm 0.10$ & $0.60 \pm 0.03$ & $19.0 \pm 12.0$ & $0.09 \pm 0.02$ & $0.03 \pm 0.01$ & $3.10 \pm 0.80$ & $0.16 \pm 0.03$ & $31.0 \pm 8.0$ & $0.36 \pm 0.02$ & $0.43 \pm 0.03$ & 6 \\
\hline C121W- $\beta 1$ Drug & $1.30 \pm 0.10$ & $0.50 \pm 0.02$ & $8.0 \pm 2.0$ & $0.20 \pm 0.03$ & $0.07 \pm 0.01$ & $1.70 \pm 0.40$ & $0.13 \pm 0.02$ & $31.0 \pm 6.0$ & $0.56 \pm 0.02$ & $0.49 \pm 0.03$ & 6 \\
\hline
\end{tabular}

${ }^{a} P<0.05$ vs. WT $\beta 1100 \mu \mathrm{M}$ Lacosamide at $34^{\circ} \mathrm{C}$.

${ }^{b} P<0.01$ vs. WT $\beta 1100 \mu \mathrm{M}$ Lacosamide at $34^{\circ} \mathrm{C}$.

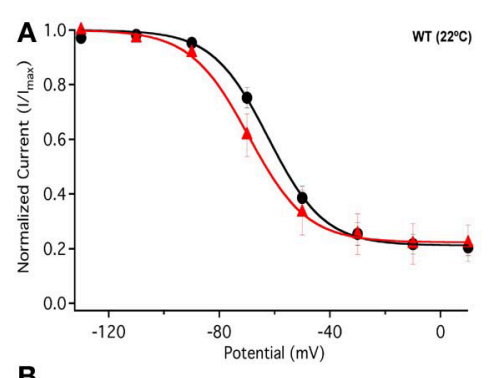

B

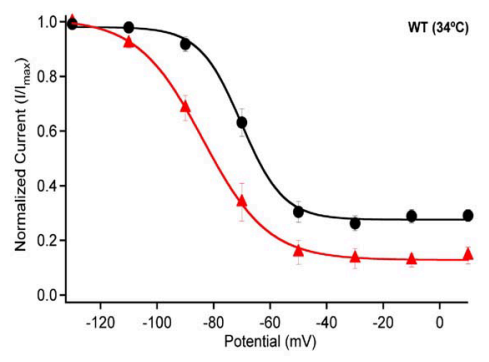

FIGURE 5 | Steady-state slow inactivation. Normalized Current is plotted against the potential $(\mathrm{mV})$. Control is shown in black circles and drug in red triangles. For both $\mathrm{WT}$ at $22^{\circ} \mathrm{C}$ and $34^{\circ} \mathrm{C}(\mathbf{A}, \mathbf{B})$ and $\mathrm{C} 121 \mathrm{~W}$ at $22^{\circ} \mathrm{C}$ and $34^{\circ} \mathrm{C}$ (C,D). Panel (D) shows an inset of the pulse protocol used to measure slow

Table 6 | Steady-state slow inactivation.

\begin{tabular}{llllr}
\hline & $\boldsymbol{V}_{\mathbf{1 / 2}}(\mathbf{m V})$ & $\boldsymbol{z}$ (slope) & plateau $\left(\boldsymbol{y}_{\mathbf{0}}\right)$ & $\boldsymbol{n}$ \\
\hline $\mathbf{2 2}^{\circ} \mathbf{C}$ & & & & \\
WT- $\beta$ 1 Control & $-61.9 \pm 2.1^{\mathrm{a}}$ & $-2.7 \pm 0.4$ & $0.21 \pm 0.03$ & 6 \\
WT- $\beta$ 1 Drug & $-68.9 \pm 2.5^{\mathrm{a}}$ & $-2.8 \pm 0.4$ & $0.22 \pm 0.07$ & 6 \\
C121W- $\beta$ 1 Control & $-62.3 \pm 2.4$ & $-3.4 \pm 0.5$ & $0.08 \pm 0.05$ & 5 \\
C121W- $\beta$ 1 Drug & $-60.7 \pm 1.6$ & $-2.7 \pm 0.2$ & $0.18 \pm 0.03$ & 8 \\
34 $^{\circ} \mathbf{C}$ & & & & \\
WT- $\beta$ 1 Control & $-70.2 \pm 0.9^{\mathrm{b}}$ & $-7.4 \pm 1.0$ & $0.27 \pm 0.03^{\mathrm{b}}$ & 7 \\
WT- $\beta$ 1 Drug & $-83.8 \pm 0.8^{\mathrm{b}}$ & $-11.5 \pm 0.7$ & $0.12 \pm 0.03^{\mathrm{b}}$ & 9 \\
C121W- $\beta$ 1 Control & $-73.9 \pm 0.5$ & $-7.6 \pm 0.5$ & $0.15 \pm 0.02$ & 7 \\
C121W- $\beta$ 1 Drug & $-77.2 \pm 0.5$ & $-10.4 \pm 0.4$ & $0.10 \pm 0.02$ & 11 \\
\hline
\end{tabular}

${ }^{a} P<0.05$ vs. WT- $\beta 1$ Control at $22^{\circ} \mathrm{C}$.

${ }^{b} P<0.001$ vs. WT $\beta 1$ Control at $34^{\circ} \mathrm{C}$.
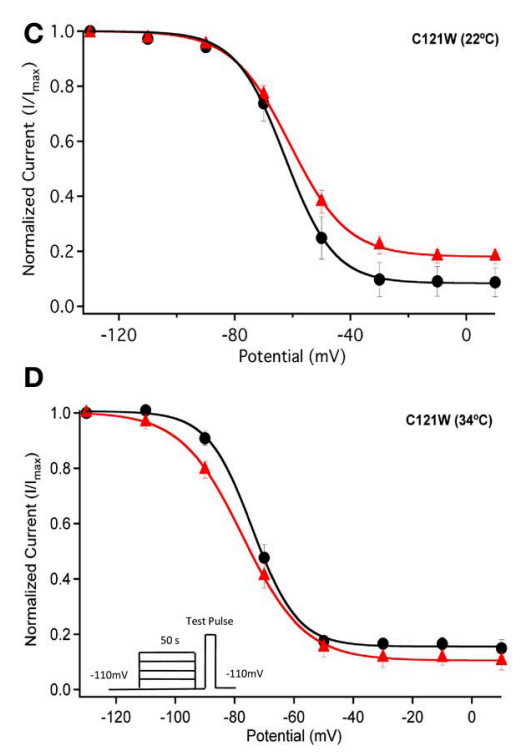

inactivation. The difference from the protocol used to measure steady-state fast inactivation is that the prepulse duration is longer ( $50 \mathrm{~s}$ ) and followed by a brief recovery pulse that recovers channels from fast inactivation prior to the test pulse.

lamotrigine (Ragsdale et al., 1996; Ragsdale and Avoli, 1998). Thus, Errington et al. (2008) showed an insignificant shift in the steady-state fast inactivation curve with $100 \mu \mathrm{M}$ lacosamide on N1E-115 neuroblastoma cells. Similarly, lacosamide had no significant effect on the steady-state fast inactivation profile in $\mathrm{Na}_{V} 1.7$ or $\mathrm{Na}_{V} 1.3$ (Sheets et al., 2008) expressed in HEK293 cells in the absence of $\beta 1$ subunits.

The results of our study generally corroborate the notion of lacosamide's specific interaction with the slow inactivation. However, in the presence of the WT- $\beta 1$ subunit we observed that even relatively short conditioning pulses $(500 \mathrm{~ms})$ are sufficient to cause a measurable effect of $100 \mu \mathrm{M}$ lacosamide on the voltage dependent availability of the channels (Figure 2A). These findings are qualitatively similar to those of Uebachs et al. (2010) who described the importance of the $\beta 1$ subunit in 

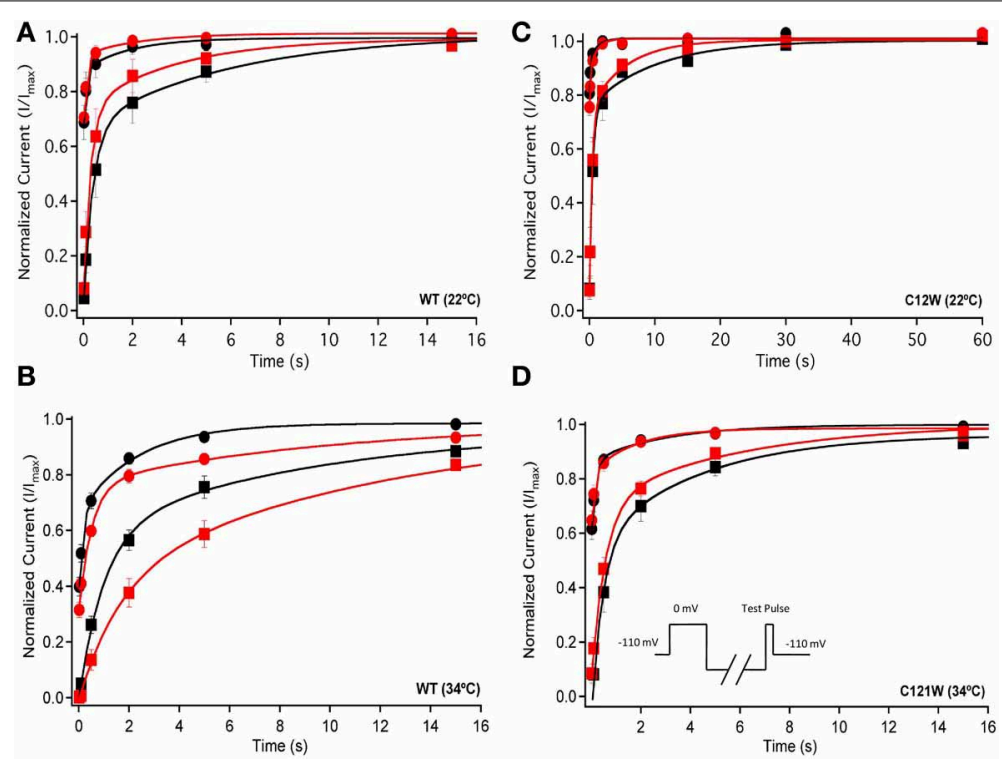

FIGURE 6 | Slow inactivation recovery. Normalized Current is plotted over the various recovery durations (s). Recovery was measured using both $500 \mathrm{~ms}$ prepulse durations (closed circles) and also $8 \mathrm{~s}$ (closed squares).

Control (black) is compared to $100 \mu \mathrm{M}$ Lacosamide (red). For both WT at $22^{\circ} \mathrm{C}$ and $34^{\circ} \mathrm{C}(\mathbf{A}, \mathbf{B})$ and $\mathrm{C} 121 \mathrm{~W}$ at $22^{\circ} \mathrm{C}$ and $34^{\circ} \mathrm{C}$ (C,D). Panel (D) shows a pulse protocol inset used to measure slow inactivation recovery.

Table 7 | Slow Inactivation Recovery.

\begin{tabular}{|c|c|c|c|c|c|c|c|c|c|c|c|}
\hline & \multicolumn{5}{|c|}{ Recovery $(500 \mathrm{~ms})$} & \multicolumn{6}{|c|}{ Recovery (8s) } \\
\hline \multicolumn{12}{|l|}{$22^{\circ} \mathrm{C}$} \\
\hline WT-1 Control & $0.09 \pm 0.02$ & $0.19 \pm 0.02$ & $1.87 \pm 0.68$ & $0.12 \pm 0.02$ & $0.99 \pm 0.01$ & $0.38 \pm 0.06$ & $0.62 \pm 0.05$ & $5.89 \pm 1.76$ & $0.34 \pm 0.05$ & $1.01 \pm 0.02$ & 5 \\
\hline WT-1 Drug & $0.13 \pm 0.03$ & $0.23 \pm 0.03$ & $2.31 \pm 1.51$ & $0.08 \pm 0.03$ & $1.01 \pm 0.01$ & $0.28 \pm 0.07$ & $0.64 \pm 0.09$ & $3.66 \pm 1.95$ & $0.26 \pm 0.09$ & $0.99 \pm 0.02$ & 5 \\
\hline C121W-1 Control & $0.09 \pm 0.06$ & $0.12 \pm 0.06$ & $1.11 \pm 1.19$ & $0.09 \pm 0.05$ & $1.01 \pm 0.01$ & $0.49 \pm 0.09$ & $0.66 \pm 0.06$ & $9.98 \pm 5.36$ & $0.24 \pm 0.05$ & $1.00 \pm 0.03$ & 5 \\
\hline WT-1 Control & $0.16 \pm 0.04^{a}$ & $0.27 \pm 0.03^{a}$ & $2.3 \pm 0.3^{b}$ & $0.32 \pm 0.03^{c}$ & $0.98 \pm 0.01$ & $1.00 \pm 0.20$ & $0.58 \pm 0.06$ & $9.0 \pm 2.0$ & $0.38 \pm 0.03^{c}$ & $0.96 \pm 0.02$ & 8 \\
\hline WT-1 Drug & $0.51 \pm 0.07^{a}$ & $0.44 \pm 0.03^{a}$ & $10.0 \pm 3.0^{b}$ & $0.22 \pm 0.02^{c}$ & $0.98 \pm 0.01$ & $1.60 \pm 0.40$ & $0.42 \pm 0.08$ & $12.0 \pm 2.0$ & $0.57 \pm 0.04^{c}$ & $0.98 \pm 0.02$ & 6 \\
\hline C121W-1 Control & $0.16 \pm 0.04$ & $0.25 \pm 0.02$ & $2.9 \pm 0.8$ & $0.13 \pm 0.02$ & $1.00 \pm 0.01$ & $0.46 \pm 0.09$ & $0.60 \pm 0.08$ & $4.0 \pm 1.0$ & $0.41 \pm 0.06$ & $0.96 \pm 0.02$ & 6 \\
\hline C121W-1 Drug & $0.12 \pm 0.03$ & $0.18 \pm 0.02$ & $1.8 \pm 0.4$ & $0.16 \pm 0.02$ & $0.98 \pm 0.01$ & $0.56 \pm 0.08$ & $0.62 \pm 0.06$ & $6.0 \pm 2.0$ & $0.29 \pm 0.06$ & $1.00 \pm 0.01$ & 7 \\
\hline
\end{tabular}

a $P<0.001$ vs. WT $-\beta 1$ Control at $34^{\circ} \mathrm{C}$.

${ }^{b} P<0.01$ vs. WT $\beta 1$ Control at $34^{\circ} \mathrm{C}$.

${ }^{c} P<0.05$ vs. WT- $\beta 1$ Control at $34^{\circ} \mathrm{C}$.

delimiting the sensitivity of $\mathrm{Nav}_{\mathrm{v}} 1.2$ to another anticonvulsant, carbamazepine.

Co-expression of the WT- $\beta 1$ subunit induces multiple effects on the kinetics of sodium channels, including accelerating fast inactivation and recovery, stabilizing steady-state fast inactivation (Tammaro et al., 2002; Aman et al., 2009; Webb et al., 2009; Egri et al., 2012), and increasing the maximum probability of slow inactivation (Vilin et al., 1999; Egri et al., 2012). Elevated temperature further accelerates the channel kinetics (Webb and Cannon, 2008; Thomas et al., 2009). As a result, at $34^{\circ} \mathrm{C}$, channels enter inactivated states faster (Figure 2A vs. B, C vs. D) and, even with relatively short conditioning pulses, the effects of $100 \mu \mathrm{M}$ lacosamide become statistically significant (Figure 2, Table 3). The trend seen in instantaneous availability curves is further supported by lacosamide slowing recovery after $500 \mathrm{~ms}$ conditioning depolarization at $34^{\circ} \mathrm{C}$ (Figure 3B).

Longer depolarization pulses favor accumulation of channels into the slow inactivated state and thus enhance the effects of $100 \mu \mathrm{M}$ lacosamide (Figures 4-6). Also, the stabilization of steady-state slow inactivation by lacosamide is more pronounced at $34^{\circ} \mathrm{C}$ (Figure 5), suggesting that higher temperature also favors slow inactivation.

The C121W mutation is located in the Ig-like domain of the $\beta 1$ subunit which is responsible for cell adhesion and aggregation, as well as $\alpha-\beta$ interactions resulting in modulation of the voltage dependence and kinetics in $\mathrm{Na}_{\mathrm{V}}$ channels (Patino and Isom, 2010). A putative structural consequence of this mutation 
is the disruption of the disulfide bond between residues 21 and 121. Functional implications include destabilization of fast and slow inactivation leading to temperature-dependent hyperexcitability of Nav1.2/C121W- $\beta 1$ channels (Egri et al., 2012). In the present study we demonstrate that the inhibitory effects of $100 \mu \mathrm{M}$ lacosamide are lost when $\mathrm{Na}_{\mathrm{V}} 1.2$ is associated with the mutant $\mathrm{C} 121 \mathrm{~W}-\beta 1$ subunit at both room temperature and $34^{\circ} \mathrm{C}$.

In conclusion, our results concur with the principal notion that lacosamide acts by stabilizing slow inactivation in Nav1.2. Our results go beyond previous studies to suggest the WT$\beta 1$ subunit indirectly modulates the efficacy of lacosamide by regulating the stability of the slow inactivation in $\mathrm{Na}_{\mathrm{V}} 1.2$ in a temperature dependent manner. The $\mathrm{C} 121 \mathrm{~W}-\beta 1$ mutation disrupts the thermoprotective role of the $\beta 1$ subunit on channel availability, which leads to hyper-excitability observed in GEFS+ (Egri et al., 2012). This implies that patients carrying $\mathrm{C} 121 \mathrm{~W}-\beta 1$ mutation may not benefit from treatment with lacosamide.

\section{ACKNOWLEDGMENTS}

Thanks to Dr. David Jones for his encouragement and support and to Dr. Yuriy Vilin for work on an earlier version of the study. Special thanks to Mr. Colin Peters for help in interpreting the results and assisting with data analysis. This study was supported by a Discovery Grant from the Natural Science and Engineering Research Council of Canada to Peter C. Ruben.

\section{REFERENCES}

Aman, T. K., Grieco-Calub, T. M., Chen, C., Rusconi, R., Slat, E. A., Isom, L. L., et al. (2009). Regulation of persistent $\mathrm{Na}$ current by interactions between \{beta\} subunits of voltagegated $\mathrm{Na}$ channels. J. Neurosci. 29, 2027-2042. doi: 10.1523/ JNEUROSCI.4531-08.2009

Audenaert, D., Claes, L., Ceulemans, B., Löfgren, A., Van Broeckhoven, C., and De Jonghe, P. (2003). A deletion in SCN1B is associated with febrile seizures and earlyonset absence epilepsy. Neurology 61, 854-856. doi: 10.1212/01.WNL. $0000080362.55784 .1 \mathrm{C}$

Catterall, W. A., Raman, I. M., Robinson, H. P. C., Sejnowski, T. J., and Paulsen, O. (2012). The hodgkin-huxley heritage: from channels to circuits. J. Neurosci. 32, 14064-14073. doi: 10.1523/JNEUROSCI.3403-12.2012

Clare, J. J., Tate, S. N., Nobbs, M., and Romanos, M. A. (2000). Voltagegated sodium channels as therapeutic targets. Drug Discov. Today 5, 506-520. doi: 10.1016/S13596446(00)01570-1

Denac, H., Mevissen, M., and Scholtysik, G. (2000). Structure, function and pharmacology of voltage-gated sodium channels. Naunyn-Schmiedeberg's Arch. Pharmacol. 362, 453-479. doi: 10.1007/s002100000319

Egri, C., Vilin, Y. Y., and Ruben, P. C. (2012). A thermoprotective role of the sodium channel $\beta 1$ subunit is lost with the $\beta 1$ (C121W) mutation. Epilepsia 53, 494-505. doi: 10.1111/j.15281167.2011.03389.x

Errington, A. C., Stohr, T., Heers, C., and Lees, G. (2008). The investigational anticonvulsant lacosamide selectively enhances slow inactivation of voltage-gated sodium channels. Mol. Pharmacol. 73, 157-169. doi: 10.1124/mol. 107.039867

Karoly, R., Lenkey, N., Juhasz, A. O., Vizi, E. S., and Mike, A. (2010). Fast- or slow-inactivated State preference of $\mathrm{Na}+$ channel inhibitors: a simulation and experimental study. PLoS Comput. Biol. 6:e1000818. doi: 10.1371/journal. pcbi. 1000818

Lees, G., and Shipton, E. (2009). Voltage-gated sodium channels in nociception and their potential as targets for new drugs in treatment of chronic neuropathic pain. Curr. Anaesth. Crit. Care 20, 204-208. doi: 10.1016/j.cacc.2009.06.002

Mantegazza, M., Curia, G., Biagini, G., Ragsdale, D. S., and Avoli, M. (2010). Voltage-gated sodium channels as therapeutic targets in epilepsy and other neurological disorders. Lancet Neurol. 9, 413-424. doi: 10.1016/S1474-4422 (10)70059-4

McCollum, I. J., Vilin, Y. Y., Spackman, E., Fujimoto, E., and Ruben, P. C. (2003). Negatively charged residues adjacent to IFM motif in the DIII-DIV linker of $\mathrm{hNa}(\mathrm{V}) 1.4$ differentially affect slow inactivation. FEBS Lett. 552, 163-169. doi: 10.1016/S0014-5793 (03)00912-8

Meisler, M. H., and Kearney, J. A. (2005). Sodium channel mutations in epilepsy and other neurological disorders. J. Clin. Invest. 115, 2010-2017. doi: 10.1172/ JCI25466

Ong, B. H., Tomaselli, G. F., and Balser, J. R. (2000). A structural rearrangement in the sodium channel pore linked to slow inactivation and use dependence. J. Gen. Physiol. 116, 653-662. doi: 10.1085/jgp. 116.5 .653
O'reilly, J. P., Wang, S. Y., Kallen, R. G., and Wang, G. K. (1999). Comparison of slow inactivation in human heart and rat skeletal muscle $\mathrm{Na}+$ channel chimaeras. J. Physiol. 515(Pt 1), 61-73. doi: 10.1111/j.1469-7793.1999.061ad.x

Patino, G. A., and Isom, L. L. (2010) Electrophysiology and beyond: multiple roles of $\mathrm{Na}$ channel [beta] subunits in development and disease. Neurosci. Lett. 486, 53-59. doi: 10.1016/j.neulet. 2010.06.050

Qin, N., D’Andrea, M. R., Lubin, M L., Shafaee, N., Codd, E. E., and Correa, A. M. (2003). Molecular cloning and functional expression of the human sodium channel beta1B subunit, a novel splicing variant of the betal subunit. Eur. J. Biochem. 270, 4762-4770. doi: 10.1046/j.1432-1033.2003.03878.x

Ragsdale, D. S., and Avoli, M. (1998). Sodium channels as molecular targets for antiepileptic drugs. Brain Res. Rev. 26, 16-28. doi: 10.1016/S0165-0173(97)00054-4

Ragsdale, D. S., McPhee, J. C., Scheuer, T., and Catterall, W. A. (1996). Common molecular determinants of local anesthetic, antiarrhythmic, and anticonvulsant block of voltage-gated $\mathrm{Na}+$ channels. J. Pharmacol. 93, 9270-9275.

Sheets, P. L., Heers, C., Stoehr, T., and Cummins, T. R. (2008). Differential block of sensory neuronal voltage-gated sodium channels by lacosamide [(2R)2-(Acetylamino)-N-benzyl-3methoxypropanamide], lidocaine, and carbamazepine. J. Pharmacol. Exp. Ther. 326, 89-99. doi: 10.1124/jpet.107.133413

Tammaro, P., Conti, F., and Moran, O. (2002). Modulation of sodium current in mammalian cells by an epilepsy-correlated beta 1-subunit mutation. Biochem. Biophys. Res. Commun. 291, 1095-1101. doi: 10.1006/bbrc.2002.6570

Thomas, E. A., Hawkins, R. J., Richards, K. L., Xu, R., Gazina, E. V., and Petrou, S. (2009). Heat opens axon initial segment sodium channels: a febrile seizure mechanism? Ann. Neurol. 66, 219-226. doi: 10.1002/ana.21712

Uebachs, M., Opitz, T., Royeck, M., Dickhof, G., Horstmann, M. T., Isom, L. L., et al. (2010). Efficacy loss of the anticonvulsant carbamazepine in mice lacking sodium channel $\beta$ subunits via paradoxical effects on persistent sodium currents. J. Neurosci. 30, 8489-8501. doi: 10.1523/JNEUROSCI.1534-10.2010

Vilin, Y. Y., Makita, N., George, A. L. Jr., and Ruben, P. C. (1999). Structural determinants of slow inactivation in human cardiac and skeletal muscle sodium channels. Biophys. J. 77, 1384-1393. doi: 10.1016/S00063495(99)76987-0

Wallace, R. H., Wang, D. W., Singh, R., Scheffer, I. E., George Jr. A. L., Phillips, H. A., et al. (1998). Febrile seizures and generalized epilepsy associated with a mutation in the $\mathrm{Na}^{+}$-channel 1 subunit gene SCN1B. Nat. Genet. 19, 366-370. doi: $10.1038 / 1252$

Webb, J., and Cannon, S. C. (2008) Cold-induced defects of sodium channel gating in atypical periodic paralysis plus myotonia. Neurology 70, 755-761. doi: 10.1212/01.wnl. 0000265397.70057.d8

Webb, J., Wu, F., and Cannon, S. C. (2009). Slow inactivation of the NaV1. 4 sodium channel in mammalian cells is impeded by co-expression of the $\beta 1$ subunit. Pflügers Arch. 457, 1253-1263. doi: 10.1007/s00424-008-0600-8 
Wimmer, V. C., Reid, C. A., Mitchell, S., Richards, K. L., Scaf, B. B., Leaw, B. T., et al. (2010). Axon initial segment dysfunction in a mouse model of genetic epilepsy with febrile seizures plus. J. Clin. Invest. 120, 2661-2671. doi: 10.1172/ JCI42219

Xu, R., Thomas, E. A., Gazina, E. V., Richards, K. L., Quick, M., Wallace, R. H., et al. (2007). Generalized epilepsy with febrile seizures plus-associated sodium channel $\beta 1$ subunit mutations severely reduce beta subunitmediated modulation of sodium channel function. Neuroscience
148, 164-174. doi: 10.1016/j. neuroscience.2007.05.038

Yu, F. H., Yarov-Yarovoy, V., Gutman, G. A., and Catterall, W. A. (2005). Overview of molecular relationships in the voltage-gated ion channel superfamily. Pharmacol. Rev. 57, 387-395. doi: 10.1124/pr. 57.4.13

Zhang, Z., Xu, Y., Dong, P. H., Sharma, D., and Chiamvimonvat, N. (2003). A negatively charged residue in the outer mouth of rat sodium channel determines the gating kinetics of the channel. Am. J. Physiol. Cell. Physiol. 284, C1247-C1254. doi: 10.1152/ajpcell.00471.2002
Conflict of Interest Statement: The authors declare that the research was conducted in the absence of any commercial or financial relationships that could be construed as a potential conflict of interest.

Received: 08 July 2013; accepted: 02 September 2013; published online: 20 September 2013.

Citation: Abdelsayed M, Sokolov $S$ and Ruben PC (2013) A thermosensitive mutation alters the effects of lacosamide on slow inactivation in neuronal voltagegated sodium channels, $\mathrm{Na}_{\mathrm{V}}$ 1.2. Front. Pharmacol. 4:121. doi: 10.3389/fphar. 2013.00121
This article was submitted to Pharmacology of Ion Channels and Channelopathies, a section of the journal Frontiers in Pharmacology.

Copyright () 2013 Abdelsayed, Sokolov and Ruben. This is an open-access article distributed under the terms of the Creative Commons Attribution License (CC BY). The use, distribution or reproduction in other forums is permitted, provided the original author(s) or licensor are credited and that the original publication in this journal is cited, in accordance with accepted academic practice. No use, distribution or reproduction is permitted which does not comply with these terms. 